\title{
A SUPERCONDUCTING 352 MHz PROTOTYPE_CAVITY FOR LEP
}

G. Arnoldb-Mayer (*), Ph. Bernard, D. Bloess, G, Caval1ari, E. Chiaveri, E. Haebel, H. Lengeler, R. Stierlin, J. Tückmantel and $W$. Weingarten CERN, Geneva, Switzerland and $H$. Piel, Univ. of Wuppertal, W.-Germany

\section{Abstract}

It is proposed to upgrade the large electronpositron storage ring LEP to energies above the initial $55 \mathrm{GeV}$ by supecconducting accelerating cavities operated at $352 \mathrm{MHz}$. A new cavity geometry has been developed which will allow to locate the main and higher order mode couplers at the beam tubes of the cavities.

Experimental results obtained with monocell cavities fabricated from niobium material of different thermal conductivity and with a 4 -cell prototype cavity are discussed.

\section{Intcoduction}

In CERN the electron positron storage ring LEP is under construction. It will start to operate in 1988 with an energy of $55 \mathrm{GeV}$ per beam. 128 copper cavities of 5 cells driven at $352 \mathrm{MHz}$ by $16 \mathrm{klystrons}$ of $1 \mathrm{~kW}$ are used to supply the energy lost each turn. The parameters of the machine will allow an energy upgrade of up to $100 \mathrm{GeV}$ per beam by installing the appropriate RF system. With this possibility in mind a research and development programme on a superconducting $R F$ system for LEP was started at CERN in 1979 [1]. The main results of this progranme can be sumarized as follows: Accelerating $\mathrm{Fields}$ of $\mathrm{S} \mathrm{MV} / \mathrm{m}$ can be obtained at an operating temperature of $4.2 \mathrm{~K}$. The independence on frequency of the results obtained and the $\mathrm{RF}$ installations already available made the choice of an operating frequency of $352 \mathrm{MHz}$ an easy one. The present plans foresee an installation of eight 4-cell cavities in the LEP machine as early as possible. This will be followed by a continuous upgrading of the beam energy using a superconducting accelerating system. Equipping the RF stations at two interaction regions with $192 \quad 4$-cell cavities would already rise particle energies to $80 \mathrm{GeV}$.

This report describes the layout, fabrication, test and experimental results of the first 4-cell prototype of a $352 \mathrm{MHz}$ superconducting LEP cavity.

\section{Design of the prototype superconducting cavity for LEP}

Based on the experience of our storage ring experiment with a 5 -eell $500 \mathrm{MHz}$ superconducting cavity in PETRA [2] we have improved our design [3]. The main aim of the modification was to remove the couplers from the cells, reduce their number to a minimum and locate them at the cut-off tubes. To keep the external $Q$ values low, one has to make sure that all modes considered dangerous are sufficiently excited in at least one cut-off tube. There they are coupled to higher order mode couplers. Modes with frequencies higher than about $1 \mathrm{GHz}$ start to propagate along the beam tube and are therefore additionally damped.

The essential features of the new design are:

The iris thickness and diameter have been modified to obtain a higher cell to cell coupling for all modes yielding a lower sensitivity to manufacturing tolerances.

(*) Scientific Associate from University of
The multimode endcell compensation [3] assures a sufficiently high field for the most important higher order modes in the cut-of tubes at the coupler location.

We decided to use 4.cell units (figs 1,2) for the application in LEP. This results in cavities which fit well in the existing machine lattice. They are also still small enough to be produced and handled with standard means and do not show significant tolerance problems which increase with the number of cells.

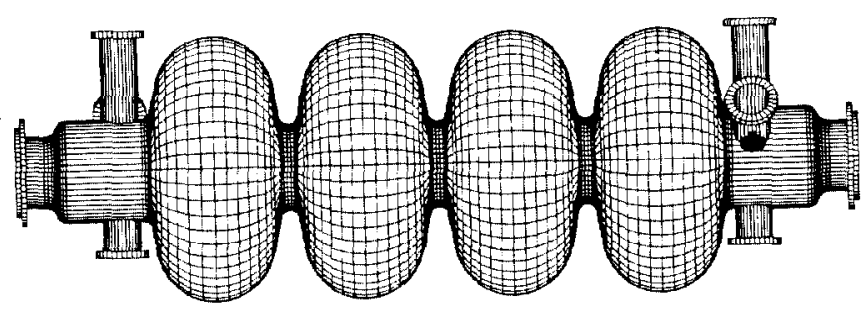

Fig. 1 sketch of the design of the superconducting $352 \mathrm{MHz}$ prototype cavity for LEP. The whole unit has a length of $2.4 \mathrm{~m}$.

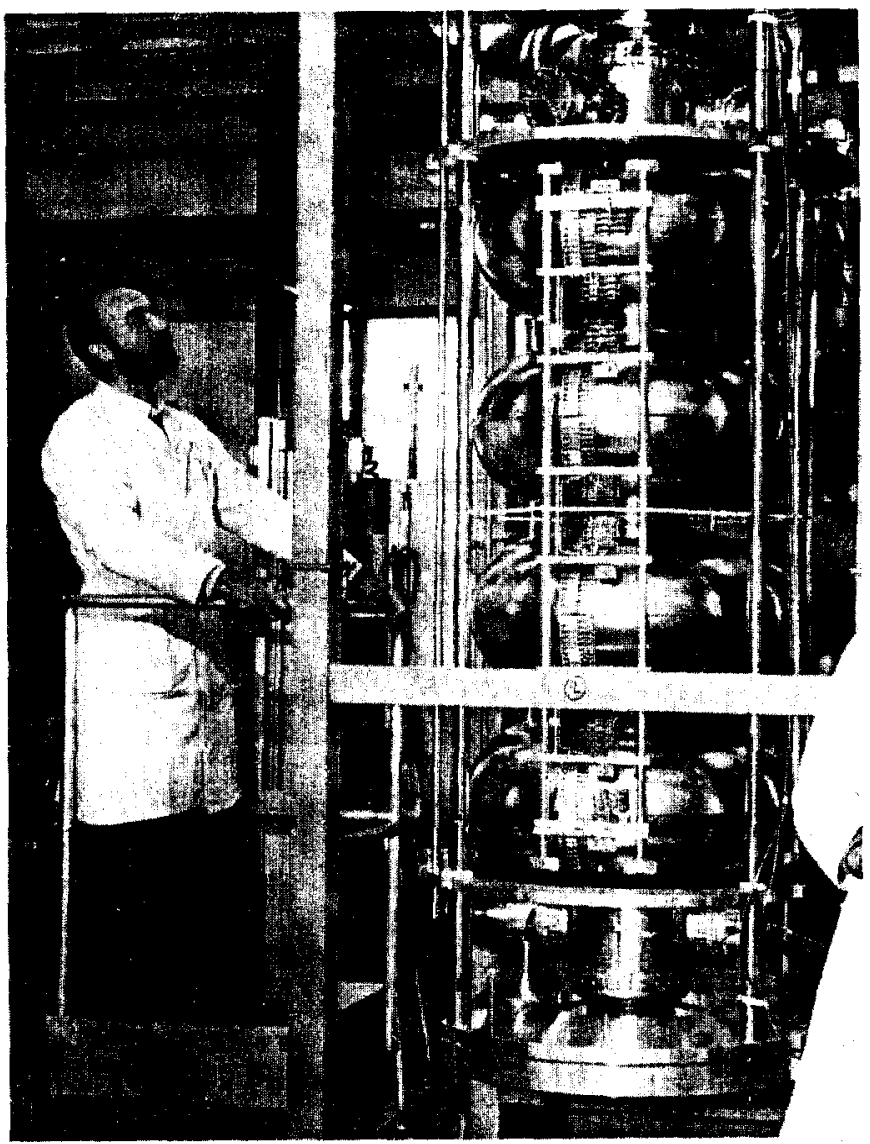

Fig. 2 The first superconducting $352 \mathrm{MHz}$ prototype cavity for LEP in its vertical support. Visible in front is the arm carrying the resistor thermometers for temperature mapping. 


\section{Mechanical and RF properties}

In order to test our design we have constructed a full scale copper model (from $3 \mathrm{~mm}$ sheet metal) and developed the corresponding couplers [4]. The copper model had a field flatness of $\pm 5 \%$ and the niabium 4-cell cavity constructed afterwards one of $\pm 6 \%$. An inelastic deformation of individual cells was not necessary. The good field flatness for both cavities shows that the production is sufficiently reproducible to guarantee a small frequency spread for the series production once the fine-tuned shape is defined.

Table 1 shows the measured $R / Q$ values of some selected modes measured in the copper model and compares them with calculated data in [3]. There is good agreement except for the TMolz mode family. The frequencies of the two highest $\mathrm{TM}_{\mathrm{OL}_{2}}$ pessband modes are very close to each other. It was therefore expected that those modes could change their field distribution significantly in a real and therefore slightly perturbed cavity. Each mode however was assumed to be strangly excited in either one or the other cut-off tube so that it can interact strongly with at least one HOM-coupler. This happened in fact as shown by the two measured field distributions in fig. 3 .

\section{TABLE 1}

(R/Q) calculated and measured in the copper model

\begin{tabular}{|c|c|c|c|c|}
\hline \multicolumn{2}{|c|}{ Mode } & $\begin{array}{l}\text { Measured } \\
(\mathrm{R} / \mathrm{Q})[\Omega]\end{array}$ & $\begin{array}{l}\text { SUPEREISH } \\
(\mathrm{R} / \mathrm{Q})[\Omega]\end{array}$ & $\begin{array}{l}\text { URMEL } \\
(R / Q) \quad[\Omega]\end{array}$ \\
\hline TH $\mathrm{H}_{11}$ & $\begin{array}{l}0 \\
\pi / 4 \\
2 \pi / 4\end{array}$ & $\begin{array}{r}112 . \\
51 . \\
7 .\end{array}$ & $\begin{array}{r}108 . \\
48.5 \\
6.4\end{array}$ & $\begin{array}{r}117.7 \\
48.0 \\
5.1\end{array}$ \\
\hline $\mathrm{TK}_{012}$ & $\begin{array}{l}2 \pi / 4 \\
3 \pi / 4 \\
\pi\end{array}$ & $\begin{array}{r}8.5 \\
17.5 \\
15 .\end{array}$ & $\begin{array}{r}22.8 \\
5.2 \\
22.7\end{array}$ & $\begin{array}{r}5.1 \\
8.0 \\
31.8\end{array}$ \\
\hline$T M_{110}$ & $3 \pi / 4$ & 12. & $5 \mathrm{~cm}$ off & $\operatorname{axis} 11.0$ \\
\hline$T M_{111}$ & 0 & 28. & $5 \mathrm{~cm}$ off & axis 25.6 \\
\hline$T M_{010}$ & $\pi$ & - & 464 & 461 \\
\hline
\end{tabular}

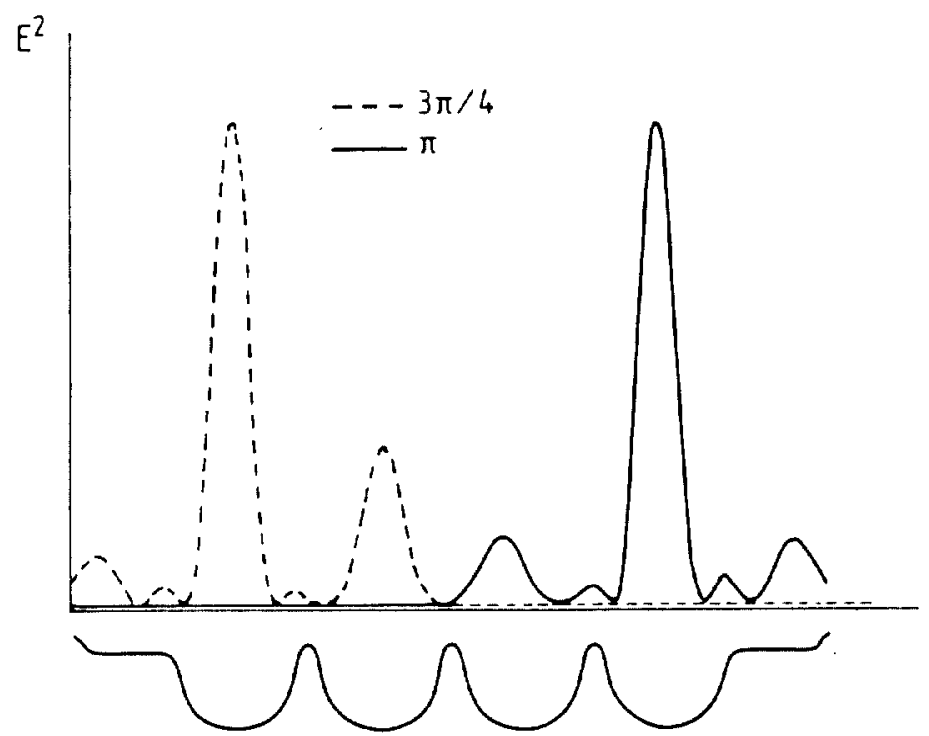

Fig. 3 Asymmetric field profiles of the $3 \pi / 4$ and I mode of the $T M_{012}$ passband.
We intend to tune our cavity in changing its total length. For the design current of LEP [5] of two times $3 \mathrm{~mA}$ and an accelerating gradient of $5 \mathrm{MV} / \mathrm{m}$ the matched loaded $Q$ will be $4 \cdot 10^{6}$ resulting in a bandwidth of about $80 \mathrm{~Hz}$. The copper model showed a frequency dependence of $45 \mathrm{~Hz}$ per $\mu \mathrm{m}$ change in length.

\section{Experiments with 352 MHz single cell cavities}

Prior to the fabrication of the niobium 4-cell cavity two single cell cavities at $352 \mathrm{MHz}$ have been tested to learn more about electron loading phenomena connected to the new geometry, to compare the Q-values at $350 \mathrm{MHz}$ for high and low thermal conductivity niobium and to gain experience with the new chemical treatment procedure [6]. One single cell cavity was made from low thermal conductivity niobium ( $10 \mathrm{~W} / \mathrm{mK}$ at $4.2 \mathrm{~K})$. A second cavity was made from niobium of improved thermal conductivity $(28 \mathrm{~W} / \mathrm{mK}$ at $4.2 \mathrm{~K})$ and was already equipped with all HOM coupling ports foreseen for the 4-cell cavity. Both cavities have been welded with the internal electron gun (see below).

Cavity No. 1 has been tested 8 times up till now, the maximum field could be improved by guided repaic from $5.5 \mathrm{MV} / \mathrm{m}$ to $10.3 \mathrm{MV} / \mathrm{m}$. The low field Q-values ranged from 3.3 to $4 \cdot 10^{\circ}$ at $4.2 \mathrm{~K}$ irrespective of the treatement applied. Cavity No 2 was tested only once and obtained immediately a field of $6.8 \mathrm{mV} / \mathrm{m}$. The low field Q-value was $2.9 \cdot 10^{9}$. In subtracting the residual losses the surface resistance of the two materials turned out to be equal within measurement error.

Both cavities showed a new type of multipacting at the equator which is described in [7]. The multipacting was observed between 3.7 and $5.4 \mathrm{MV} / \mathrm{m}$ and could always be overcome by RF processing. This limitation did not reappear provided the cavity remained at $4.2 \mathrm{~K}$. It was first observed in a horizontally dried cavity at the point of the equator, which was lowest during drying. From then on we dried the cavities in an inclined position, so that drying residues would concentrate at regions where multipacting does not occur.

\section{Methods of fabrication and surface treatement}

The niobium 4-cell cavity was constructed according to our standard technique and quality control [8] with two major exceptions. The first was the use of high thermal conductivity niobium sheet material of $3 \mathrm{~mm}$ thickness which was also easier to spin because of its lower elastic limit. The second was a change in the electron beam welding technique.

The iris diameter of about $240 \mathrm{~mm}$ allowed the use of an "internal electron gun"(*) so that all weldings could be done from inside. With this method the allowed range of welding parameters is broader and the beam-power is lower since a full penetration is not absolutely necessary. All weldings were done with a voltage of $25 \mathrm{kV}$, a current of $85 \mathrm{~mA}$ and a welding speed of $3 \mathrm{~mm} / \mathrm{sec}$. The smoothest welding surface was obtained with the electron beam oriented horizontally and slightly defocalised with the cavity moving such that the welding pool was rising.

The half-celis were welded together to full cells, inspected and ground if necessary. All four cells and the cut-off tubes already equipped with coupling ports were mounted into a specially designed rotating support. Then the irises were welded consecutively with

(*) Kindly lent to us by SCIAKY corporation, Paris. 
the internal gun, each weld followed by an inspection and grinding if necessary.

Our standard chemical etching had to be modified. The cavity has a volume of about $\$ 701$ so that filling and draining takes $5 \mathrm{~min}$. each. Therefore we used a mixture of $\mathrm{HF}, \mathrm{HNO}_{3}$ and $\mathrm{H}_{3} \mathrm{PO}_{4}$ in the volume ratio $1: 1: 2$ giving a slower etching rate.

The cavity was finally rinsed with 4901 of high purity dust-filtered water in front of a laminar air-flow. The drained water reached a resistivity of $3.5 \mathrm{~cm}$ at the end. The cavity was dried in the clean room in an inclined position.

\section{Cold measurement of the 4-cell cavity}

The first test of the superconducting prototype cavity for LEP was done in April 1985 and the design field of $5 \mathrm{MV} / \mathrm{m}$ at a Q-value of $3 \cdot 10^{\circ}$ was obtained.

The cavity was tested in a vertical test-cryostat. The low field Q-value of the cavity immediately after cool-down was $4.2 \cdot 10^{\circ}$. When increasing the field, non-resonant electron loading started at about $1 \mathrm{mV} / \mathrm{m}$, therefore helium ion sputtering [9] was applied for an extended period of time. During processing modes of the fundamental passband were changed in order to assure the optimum sputtering rate at the lawest radiation level. Fig. 4 shows the accelerating field measured at a $Q$ of $1 \cdot 10^{9}$ as a function of the processing time. After $73 \mathrm{~h}$ of processing $6 \mathrm{kV} / \mathrm{m}$ at a $Q$ of $1.4 \cdot 10^{\circ}$ were obtained. Although there is no indication of a ceduction in processing speed we have stopped this procedure because the design values were reached.

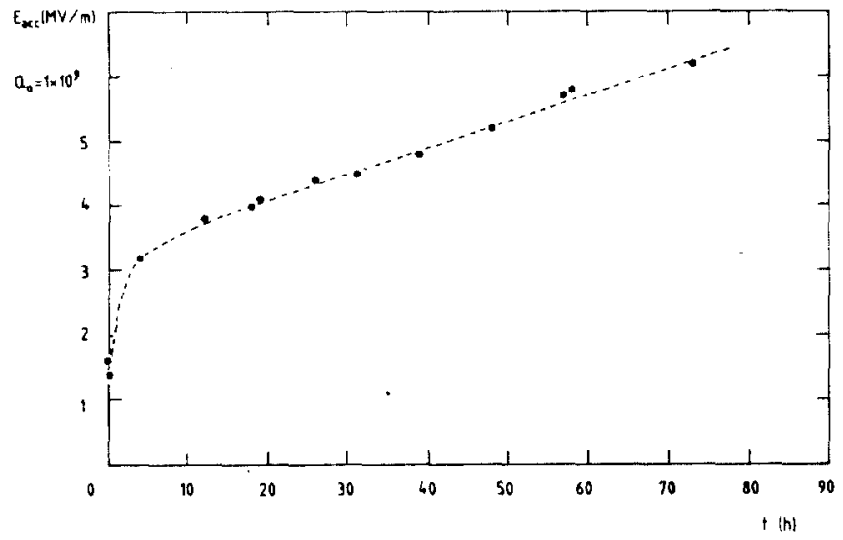

Fig. 4 Accelerating field at $Q=1 \cdot 10^{\circ}$ as a function of the processing time ( $T=4.2 \mathrm{~K})$.

During the processing the multipacting level already known from the single cell measurements appeared but it was processed in parallel with the field emitters and did not influence the cavity's performance any more at the end of the processing period.

Fig. 5 shows the finally obtained Q-value as a function of the accelerating gradient at $4.2 \mathrm{~K}$. The low field Q-value is $4.7 \cdot 10^{\circ}$ and reduces to $3.3 \cdot 10^{9}$ at the design field of $5 \mathrm{kV} / \mathrm{m}$. The next experiment will be a continuation of the helium ion sputtering and an investigation of the cavity with temperature mapping.

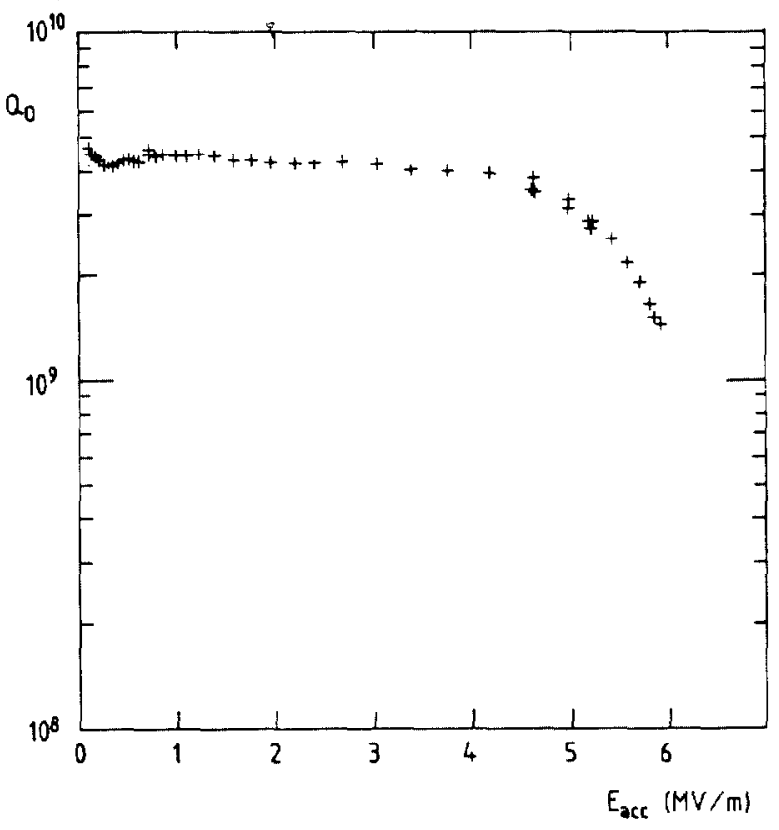

Fig. 5 Q value of the cavity as a function of the accelerating field $(\mathrm{T}=4.2 \mathrm{~K}$ ).

\section{Conclusions}

The test of the first superconducting prototype cavity for Lep demonstrated that the design accelerating field of $5 \mathrm{kv} / \mathrm{m}$ at a cavity $Q$ of $3 \cdot 10^{9}$ can be obtained with fabrication and surface treatment procedures applicable to large scale production. The next step will be the transfer of this technology to industry in order to prepare for the production of eight 4-cell units to be installed in the LEP machine by the end of 1988 .

\section{Acknowledgements}

We thank all technicians of our group for their help. We would also like to thank the technicians from AT and cryogenics groups of EF Division as well as all members of $E F$ and $S B$ workshops involved in the programe.

\section{References}

[1] Ph. Bernard et al., Proc. lith Int. Conf. on High Energy Accelerators, Geneva (1980) 878.

[2] Ph. Bernard et a1, Proc, of 1983 Particle Accel. Conf., Santa Fe (1983) 3342

[3] E. Haebel, P. Marchand and J. Tückmantel, Froc. of the Second Workshop on RF Superconductivity CERN, Geneva (1984) 281

[4] E. Haebel, to be published.

[5] LEP design report, CERN-LEP/84-01, June 1984, vol. 2 .

[6] D. Bloess et al., CERN/EF/RF (to be published).

[7] W. Weingarten, Proc. of the Second Workshop on RE superconductivity, CERN, Geneva (1984) 551.

[8] Ph. Bernard et al, Nucl. Instr. and Meth. 190 (1981) 257 .

[9] H.A. Schwettmann, J.P. Turneaure and R.F. Waites, Journ. of Appl. Phys., vol, 45, February 1974, 914. 